\title{
Evaluation of a pilot healthy eating intervention in restaurants and food stores of a rural community: a randomized community trial
}

\author{
Ana P Martínez-Donate ${ }^{1 *}$, Ann Josie Riggall ${ }^{1}$, Amy M Meinen², Kristen Malecki ${ }^{1}$, Anne L Escaron ${ }^{3}$, Bev Hall4,
} Anne Menzies ${ }^{4}$, Gary Garske ${ }^{5}$, F Javier Nieto ${ }^{1}$ and Susan Nitzke ${ }^{6}$

\begin{abstract}
Background: Research suggests that the food environment influences individual eating practices. To date, little is known about effective interventions to improve the food environment of restaurants and food stores and promote healthy eating in rural communities. We tested "Waupaca Eating Smart " (WES), a pilot intervention to improve the food environment and promote healthy eating in restaurants and supermarkets of a rural community. WES focused on labeling, promoting, and increasing the availability of healthy foods.
\end{abstract}

Methods: We conducted a randomized community trial, with two Midwestern U.S. communities randomly assigned to serve as intervention or control site. We collected process and outcome data using baseline and posttest owner and customer surveys and direct observation methods. The RE-AIM framework was used to guide the evaluation and organize the results.

Results: Seven of nine restaurants and two of three food stores invited to participate in WES adopted the intervention. On a $0-4$ scale, the average level of satisfaction with WES was $3.14(S D=0.69)$ for restaurant managers and $3(S D=0.0)$ for store managers. On average, 6.3 ( $S D=1.1$ ) out of 10 possible intervention activities were implemented in restaurants and 9.0 ( $\mathrm{SD}=0.0$ ) out of 12 possible activities were implemented in food stores. One month after the end of the pilot implementation period, $5.4(\mathrm{SD}=1.6)$ and $7.5(\mathrm{SD}=0.7)$ activities were still in place at restaurants and food stores, respectively. The intervention reached $60 \%$ of customers in participating food outlets. Restaurant food environment scores improved from 13.4 to $24.1(p<0.01)$ in the intervention community and did not change significantly in the control community. Food environment scores decreased slightly in both communities. No or minimal changes in customer behaviors were observed after a 10-month implementation period.

Conclusion: The intervention achieved high levels of reach, adoption, implementation, and maintenance, suggesting the feasibility and acceptability of restaurant-and food store-based interventions in rural communities. Pilot outcome data indicated very modest levels of effectiveness, but additional research adequately powered to test the impact of this intervention on food environment scores and customer behaviors needs to be conducted in order to identify its potential to promote healthy eating in rural community settings.

Keywords: Healthy eating, Food environment, Restaurant interventions, Food store interventions, Rural communities

\footnotetext{
* Correspondence: martinezdona@wisc.edu

${ }^{1}$ Department of Population Health Sciences, University of Wisconsin,

Madison, WI, USA

Full list of author information is available at the end of the article
}

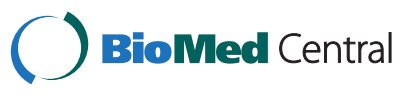

(c) 2015 Martínez-Donate et al.; licensee BioMed Central. This is an Open Access article distributed under the terms of the Creative Commons Attribution License (http://creativecommons.org/licenses/by/4.0), which permits unrestricted use, distribution, and reproduction in any medium, provided the original work is properly credited. The Creative Commons Public Domain Dedication waiver (http://creativecommons.org/publicdomain/zero/1.0/) applies to the data made available in this article, unless otherwise stated. 


\section{Background}

Obesity is a complex public health problem with serious health and economic consequences [1,2]. In the US, over two thirds of adults are overweight or obese [3]. The problem is even more acute in rural areas where obesity rates tend to be higher [4] and resources for obesity prevention efforts are typically scarcer [5]. Research indicates that a healthy diet plays a critical role in preventing obesity and chronic diseases, however almost all Americans fail to adhere to dietary recommendations [6].

Growing evidence indicates that the nutrition environment, encompassing food access, availability, pricing, quality, and promotion, [7] is linked to individual dietary behaviors $[8,9]$ and obesity rates [10]. Restaurants and food stores are two main domains of the community nutrition environment [7] and represent suitable settings for interventions aimed to promote healthier dietary practices and curb the obesity epidemic at a population level.

Previous research on community-based interventions promoting healthy eating in restaurants and stores has provided some evidence of feasibility, but data on their effectiveness to positively alter the nutrition environment and patrons' purchasing behaviors is still inconclusive [11-13]. While evidence supporting these interventions is growing, gaps remain in the literature. For instance, although 19\% of Americans live in rural areas [14] and 40\% of rural adults are obese, [4] few studies have evaluated restaurant or store interventions in rural or semi-rural areas [15]. Additionally, almost all interventions have focused exclusively on either restaurants or food stores, missing the opportunity for synergy between these two domains. Furthermore, there is a need for stronger and more comprehensive evaluation designs using baseline measures, comparison groups, and data beyond efficacy or effectiveness to better assess the public health impact of these interventions $[13,16]$.

The purpose of this study is to pilot test a communitylevel intervention to improve the nutrition environment and promote healthy eating in restaurants and food stores of a rural community. The evaluation emphasized acceptability and feasibility and was guided by the RE-AIM framework, [17] a model that considers the public health impact of an intervention as determined not only by its effectiveness or efficacy, but also by the ability to reach the intended audience (Reach), the likelihood of being adopted by the intended organizations or settings (Adoption), the extent and fidelity of implementation (Implementation), and the likelihood of being sustained over time (Maintenance). By attending to these multiple dimensions for an intervention designed to meet the needs of a rural community, our study was designed to inform a future effectiveness trial aimed to expand the evidence base related to community-based approaches to promote healthy eating and curb the obesity epidemic in rural U.S. communities.

\section{Methods}

\section{Study design}

A pilot randomized community trial was conducted in two Midwestern rural communities randomly assigned to serve as either an intervention or a control site. The two communities were located about thirty miles apart in adjacent counties. They were selected based on their relatively small population size (6,000 to 26,000 residents), similar socio-demographic profile, presence of an active Nutrition and Physical Activity (NPA) coalition, and absence of other major healthy eating initiatives prior to the beginning of the study. Seven restaurants and two food stores agreed to participate in the intervention community; likewise seven restaurants and two food stores matched in approximate customer volume were recruited to serve as comparison sites in the control community. Multi-modal methods were used for evaluation of the intervention on the RE-AIM dimensions (Table 1). All study procedures were approved by the Institutional Review Board at the University of Wisconsin-Madison.

\section{Waupaca Eating Smart}

Waupaca Eating Smart (WES) was a pilot intervention developed by a university-based academic team and two local nutrition and physical activity (NPA) coalitions. WES was informed by a formative assessment and guided by a social ecological model (SEM). The SEM posits that health behaviors are the result of the interplay between individual attributes (i.e. knowledge, attitudes, etc.) and environmental factors, with emphasis on the role of social, policy, and built environment factors [18]. We used a participatory research approach, [19] characterized by equitable collaboration between community members and researchers in all aspects of the research process [20]. WES also incorporated social marketing methods [21]. Social marketing is the application of commercial marketing techniques to positively influence health behaviors, using a consumeroriented process and targeting changes in social norms as a mechanism to change behaviors [22]. WES was implemented simultaneously in 9 food retail establishments (i.e. 7 restaurants and 2 supermarkets) from October 2011 through July 2012. Core WES strategies included increasing availability, point-of-purchase/labeling, and promotion of healthier items in local restaurants and grocery stores. Specific intervention activities, such as displaying a window cling or using menu inserts, were implemented for each of these broad strategies (See Table 2 for a complete list of WES strategies). To formally participate in WES, restaurant and store managers signed a written agreement to implement a minimum of 3 intervention activities and participate in the evaluation of WES. 
Table 1 Evaluation of WES along RE-AIM dimensions

\begin{tabular}{|c|c|c|c|}
\hline RE-AIM dimension & Definition & Data source & Evaluation \\
\hline Reach & $\begin{array}{l}\text { Percent and characteristics } \\
\text { of individuals reached by } \\
\text { an intervention }\end{array}$ & Customer surveys & $\begin{array}{l}\text { Descriptive statistics of post-test customer } \\
\text { awareness, logo recognition, and assessment } \\
\text { of materials (understandable, appealing, helpful) }\end{array}$ \\
\hline \multicolumn{4}{|l|}{ Effectiveness } \\
\hline $\begin{array}{l}\text { - Environment (nutrition } \\
\text { environment) }\end{array}$ & $\begin{array}{l}\text { Changes in nutrition environment } \\
\text { scores attributable to intervention }\end{array}$ & NEMS data & $\begin{array}{l}\text { Paired t-tests of pre/post nutritional environment } \\
\text { scores stratified by community }\end{array}$ \\
\hline $\begin{array}{l}\text { - Individual (customer and } \\
\text { owner behaviors and } \\
\text { theoretical mediators) }\end{array}$ & $\begin{array}{l}\text { Changes in customer behaviors } \\
\text { and attitudes attributable to } \\
\text { intervention }\end{array}$ & $\begin{array}{l}\text { Customer surveys } 1 \text {-month and } \\
10 \text {-months after the intervention }\end{array}$ & $\begin{array}{l}\text { Adjusted multiple regression models of customer } \\
\text { satisfaction and choices }\end{array}$ \\
\hline Adoption & $\begin{array}{l}\text { Percent and characteristics of } \\
\text { outlets of settings that agreed } \\
\text { to participate }\end{array}$ & Program records & $\begin{array}{l}\text { Descriptive statistics of managers approached that } \\
\text { agreed to participate in the intervention }\end{array}$ \\
\hline Implementation & $\begin{array}{l}\text { Extent to which intervention } \\
\text { is implemented as planned }\end{array}$ & $\begin{array}{l}\text { Direct observation after 5-month } \\
\text { intervention period }\end{array}$ & $\begin{array}{l}\text { Descriptive analysis of strategy implementation } \\
\text { by food outlet and by strategy }\end{array}$ \\
\hline \multirow[t]{2}{*}{ Maintenance } & $\begin{array}{l}\text { Extent to which intervention is } \\
\text { likely to be sustained over time }\end{array}$ & $\begin{array}{l}\text { Direct observation after 10-month } \\
\text { intervention period }\end{array}$ & Descriptive analysis of strategy implementation \\
\hline & & Owner surveys & $\begin{array}{l}\text { Descriptive analyses of manager interest in } \\
\text { continued participation at post-test }\end{array}$ \\
\hline
\end{tabular}

Table 2 Selection, implementation, and maintenance of WES strategies across outlets and time points: direct observation data

\begin{tabular}{|c|c|c|c|c|c|c|c|}
\hline \multirow[t]{2}{*}{ Possible restaurant strategies } & \multicolumn{3}{|c|}{ Restaurants selecting and implementing } & \multirow[t]{2}{*}{ Possible store strategies } & \multicolumn{3}{|c|}{ Stores selecting and implementing } \\
\hline & $\begin{array}{l}\text { Initially } \\
\text { selected }^{a}\end{array}$ & $\begin{array}{l}\text { Observed } \\
\text { at mid }\end{array}$ & $\begin{array}{l}\text { Observed } \\
\text { at post }\end{array}$ & & $\begin{array}{l}\text { Initially } \\
\text { selected }^{\text {a }}\end{array}$ & $\begin{array}{l}\text { Observed } \\
\text { at } \text { mid }^{\text {b }}\end{array}$ & $\begin{array}{l}\text { Observed } \\
\text { at post }\end{array}$ \\
\hline Window cling & 7 & 7 & 7 & Window cling & 2 & 2 & 2 \\
\hline Signs on the counter & 2 & 4 & 3 & Signs on service counter & 2 & 2 & 2 \\
\hline Signs by the register & 2 & 3 & 0 & Signs by registers & 2 & 2 & 2 \\
\hline Menu stickers & 3 & 1 & 2 & Staff wears WES pins & 0 & 0 & 0 \\
\hline Menu inserts & 6 & 3 & 2 & Signs for local produce & 1 & 0 & 0 \\
\hline Table tents & 4 & 5 & 5 & Point-of-purchase signs & 2 & 2 & 2 \\
\hline Promotion of WES items by wait staff & 7 & 0 & 0 & Healthy recipes & 2 & 2 & 2 \\
\hline Wait staff can explain WES* & 7 & 7 & 6 & $\begin{array}{l}\text { Shopping list for healthy } \\
\text { recipes }\end{array}$ & 0 & 0 & 0 \\
\hline $\begin{array}{l}\text { Wait staff can recommend WES } \\
\text { items* }\end{array}$ & 7 & 7 & 6 & In-store display ${ }^{* *}$ & 2 & 2 & 2 \\
\hline \multirow{5}{*}{$\begin{array}{l}\text { Restaurant offers one or more WES } \\
\text { meal }\end{array}$} & 7 & 7 & 7 & Bag stuffers ${ }^{* *}$ & 2 & 2 & 0 \\
\hline & & & & Staff can explain WES* & 2 & 2 & 2 \\
\hline & & & & $\begin{array}{l}\text { Staff can recommend } \\
\text { WES items* }\end{array}$ & 2 & 2 & 1 \\
\hline & \multicolumn{3}{|c|}{$\begin{array}{l}\text { Strategies in restaurants } \\
\text { (Out of } 10 \text { possible strategies) }\end{array}$} & & \multicolumn{3}{|c|}{$\begin{array}{l}\text { Strategies in stores } \\
\text { (Out of } 12 \text { possible strategies) }\end{array}$} \\
\hline & Initially selected $^{\text {d }}$ & $\operatorname{Mid}^{\mathrm{e}}$ & Post $^{f}$ & & Initially selected $^{d}$ & Mid $^{\mathrm{e}}$ & Post $^{f}$ \\
\hline $\begin{array}{l}\text { Total Number of Strategies, } \\
\text { Mean (SD) }\end{array}$ & $7.73(1.29)$ & $6.29(1.11)$ & $5.43(1.62)$ & & $9.5(0.5)$ & $9.0(0.0)$ & $7.5(0.7)$ \\
\hline
\end{tabular}

${ }^{a}$ Number of outlets selecting each strategy prior to launching the intervention.

${ }^{\mathrm{b}}$ Number of outlets implementing the strategy at mid-intervention point (5 months after launching the intervention).

${ }^{b}$ Number of outlets implementing the strategy at post-intervention point (10 months after launching the intervention).

${ }^{d}$ Average number of intervention strategies per outlet selected prior to launching the intervention.

${ }^{\mathrm{e}}$ Average number of intervention strategies per outlet implemented at mid-intervention point (5 months after launching the intervention).

${ }^{f}$ Average number of intervention strategies per outlet implemented at post-intervention point (10 months after launching the intervention).

*Assessed upon probing by WES staff during audit.

**Assessed based on observation by WES staff and/or reports from outlet managers. 
Nutrition criteria were developed by reviewing those included in other healthy eating interventions [23,24] and considering what may be feasible and sustainable in the intervention community. "WES-approved" bundled meals (entrée and side dish) contained less than 700 calories and included a cup of fruit or vegetables (excluding French fries); "WES-approved" side dishes contained less than 300 calories and included a half-cup of fruit or vegetables.

A local registered dietitian in the NPA coalition analyzed menu items at individual restaurants to identify or create one to three "WES-approved" meals at each restaurant. Promotional and point-of-purchase materials including window clings, table tents, menu stickers, and menu inserts were developed by the academic team and NPA coalition to identify and promote these meals and other healthy eating practices. At food stores, bi-monthly displays staffed by the NPA coalition offered samples of WES side dishes prepared by the store; WES materials included signs for produce, recipes for bundled meals, and fliers with healthy eating tips.

Additional promotional activities were implemented at the community level to influence social norms regarding healthy eating. The NPA coalition selected a local, wellknown, member of the community to help promote WES. This local "celebrity" promoted WES by eating at each WES restaurant twice over the evaluation period and writing a total of 14 articles in the local newspaper about his experience. An additional six newspaper articles published in local media featured WES. A blog and Facebook page promoted WES by circulating articles, healthy eating tips, recipes, and information about WES. Additional details on WES development process and content are presented elsewhere [25].

\section{Evaluation procedures and measures Customer surveys}

For evaluation of customer-level reach and effectiveness, we conducted interviewer-administered pre-and posttest intercept surveys with convenience samples of customers in the intervention and comparison outlets. Approximately thirty customer surveys per outlet were completed during a two-week period 1-month before and 10-months after implementation of the intervention. A minimum of two survey shifts were purposely selected to cover an equal number of lunch and dinner times for restaurants (morning, midday, and evening times for stores), as well as weekdays and weekend days, in each food outlet. During each selected survey shift, each customer exiting the food outlet was approached consecutively, screened for eligibility (i.e. 18 years or older, fluent in English, and having just eaten or purchased food in the restaurant or store), and invited to complete a paper-based self-administered anonymous survey. Verbal consent was obtained from survey participants. The survey took an average of 6-7 minutes to complete. Customers who completed the survey received a $\$ 2$ gift certificate for the food outlet.

Pretest and post-test intercept customer surveys included questions on satisfaction with healthy options available, perceived healthiness of the foods purchased, and whether they purchased any foods promoted as healthy in the outlet. At post-test in the intervention community only, questions also asked about WES name and logo recognition, exposure to WES activities/materials/messages, and, among those exposed, degree of appeal, ease of interpretation, helpfulness to decide purchase, and whether the respondent ordered/purchased any WES foods. Answers included five-point Likert scales (e.g., $0=$ not a lot to 4=a great deal) or Yes/No choices.

\section{Nutrition environment measures}

To evaluate the impact of WES on the food environment we used the Nutritional Environment Measures Surveys (NEMS). The NEMS has been previously validated, showing high degrees of inter-rater and test-retest reliability, and good validity properties [26,27]. One month before and 10 months after launching of WES, a trained research assistant assessed the food environment in participating outlets in the intervention and comparison communities using NEMS. The rater was external to the research team and not informed about the WES or the purpose of the environment audit prior to conducting the assessments. NEMS is an observational audit tool of nutrition environments. Restaurants received points for a variety of measures related to availability of healthier foods, pricing, nutrition information or healthy symbols, and signage facilitating healthy eating (up to 90 points). Stores received points for availability, pricing, and quality of healthier foods (up to 66 points). For both, restaurant and stores, higher overall scores represent conditions more conducive to healthy eating $[26,27]$.

\section{Manager surveys}

For evaluation of implementation and maintenance, postintervention interviewer-administered surveys were conducted with owners, operators, or managers (hereafter referred to as "managers") of participating outlets at the intervention community $(n=9)$. Written consent was obtained prior to enrollment. No incentives were offered to managers for completing the surveys. Post-intervention manager survey questions included intentions to continue implementing WES (from $0=$ not likely to $4=$ very likely), perceived impact on their business $(0=$ very negative to 4 very positive), and overall satisfaction with WES ( $0=$ not at all to $4=$ a great deal).

\section{Direct observation of WES implementation}

Coalition members completed unannounced visits to WES outlets to conduct direct observation of WES activity 
implementation at mid-intervention point (i.e. 5 months after launching of WES) and at posttest (i.e. 10 months after the intervention). Using a checklist, coalition members noted whether the activities were in place or ongoing at the time of the visit (possible activities are listed in Table 2). Based on these observations, each of the possible strategies was coded as $1=$ implemented or $0=$ not implemented on the participating outlets by midintervention and post-intervention point.

\section{Analysis}

Descriptive statistics were estimated to evaluate reach, adoption, implementation, and maintenance. To measure intervention effects on restaurant nutrition environments, paired t-tests were conducted separately for each community. Given the small number of supermarkets $(\mathrm{N}=4)$, descriptive statistics were used in place of formal statistical testing to examine changes in store nutrition environments.

This pilot study was not powered to detect significant differences in outcomes, but to test the feasibility and acceptability of WES and inform a future effectiveness study. However, we explored intervention effects on customer satisfaction, perceptions, and behaviors, using multiple linear and logistic regression models. The main predictors were the community (intervention versus comparison), time (pretest versus post-test), and intervention effect (interaction term community*time). Regression models accounted for the clustering of the data within outlets and were adjusted for age, gender, education, whether the participant was a local community resident or a visitor, and day of the survey (weekend versus weekday). For restaurants, models were further adjusted for time of day (breakfast/lunch versus dinner time) and whether participants were celebrating a special event or holiday (yes versus no) at their most recent meal in the restaurant. All analyses were conducted with Stata/SE 12.0 for Mac (StataCorp, LP, College Station, TX).

\section{Results}

\section{Adoption}

Seven (78\%) out of nine restaurants and two (67\%) out of three food stores approached for participation signed written agreements to participate in WES. Of the restaurants, six were locally owned single-unit restaurants and one was a franchise chain restaurant. Participating restaurants represented a range of outlets including one fastcasual restaurant and six sit-down restaurants, which included three American style restaurants, two cafés, and one pizza restaurant. The two restaurants that declined participation were American style sit down restaurants. The two food stores that participated were both larger chain grocery stores. One was a corporate store and the other was a franchise. The food store declining participation was a convenience store. Participating outlets represented a third of all restaurants and the two largest food stores in the intervention community.

\section{Implementation \& maintenance WES activities observed}

None of the WES activities were found to be in place in restaurants or stores prior to the intervention. After launching of WES, all restaurants successfully implemented several broad strategies, including offering healthy bundled meals, training wait staff to promote the program, and displaying promotional materials around the restaurant. Out of a possible 10 WES activities offered to the outlets, on average restaurants selected 7.42 (range 7-9) strategies prior to the beginning of the intervention, had implemented 6.3 (range 5-8) activities by mid intervention point, and, of these, 5.4 (range 2-7) activities remained in place one month post-intervention (Table 2).

The two supermarkets also implemented a number of activities, including offering recipes and shopping lists for healthy bundled meals, offering in-store displays with healthy samples, placing promotional materials around the store, providing bag stuffers with healthy tips, and posting point-of-purchase signs for fruits and vegetables (Table 2). Out of a possible 12 activities, stores selected 9.5 (range 9-10) strategies prior to launching of WES, had implemented 9 activities by mid intervention point (9 at both stores) and, of these, 7.5 activities remained in place one month post-intervention (range 7-8).

\section{Manager intention to sustain WES}

Managers were 42 years old on average $(S D=7.32)$. Five (56\%) were males and four were females (44\%). About $44 \%$ had completed at least some college studies. Five $(33 \%)$ were owners and four $(44 \%)$ were managers. On a $0-4$ scale $(0=$ not likely, $4=$ very likely), the average likelihood of continuing implementing WES at the end of the 10 -month evaluation period was $2.86(\mathrm{SD}=0.90)$ for restaurant managers and 3.5 for store managers $(\mathrm{SD}=0.71)$. On a 0 (very negative) to 4 (very positive) scale, the average impact on business was $3.0(\mathrm{SD}=0.0)$ and $2.0(\mathrm{SD}=0.0)$ for restaurant and store managers, respectively. The average level of satisfaction with WES was 3.14 for restaurant managers $(\mathrm{SD}=0.69)$ and $3(\mathrm{SD}=0.0)$ for store managers, on a 0 to 4 scale $(0=$ not at all, $4=$ a great deal $)$.

\section{Reach}

We obtained a response rate of $50.3 \%$ and $38.5 \%$ for customer surveys in restaurants and stores, respectively. Samples sizes, demographic, and contextual characteristics of survey respondents are shown in Table 3.

At post-test in the intervention community, 51.0\% of exiting restaurant customers $(\mathrm{N}=151)$ reported they had heard of WES, 60.9\% recognized the WES logo, and $36.9 \%$ had noticed the WES logo in the restaurant they 
Table 3 WES customer intercept surveys: demographic and contextual characteristics

\begin{tabular}{|c|c|c|c|c|c|c|c|c|}
\hline \multirow[b]{3}{*}{ Variable } & \multicolumn{4}{|c|}{ Restaurant customers } & \multicolumn{4}{|c|}{ Store customers } \\
\hline & \multicolumn{2}{|c|}{ Intervention community } & \multicolumn{2}{|c|}{ Comparison community } & \multicolumn{2}{|c|}{ Intervention community } & \multicolumn{2}{|c|}{ Comparison community } \\
\hline & Pre $(n=168)$ & Post $(n=151)$ & Pre $(n=215)$ & Post $(n=187)$ & Pre $(n=96)$ & Post $(n=203)$ & Pre $(n=99)$ & Post $(n=203)$ \\
\hline Gender (female), \% & 60.8 & 64.2 & 61.0 & 67.2 & 75.8 & 73.9 & 72.2 & 68.7 \\
\hline Age, Mean (SD) & $55.0(14.8)$ & $56.2(18.1)$ & $50.6(18.3)$ & $52.3(18.7)$ & $56.7(15.1)$ & $58.9(15.2)$ & $54.0(16.9)$ & $55.1(17.5)$ \\
\hline $\begin{array}{l}\text { Education (completed college } \\
\text { degree), \% }\end{array}$ & 44.6 & 39.1 & 46.0 & 53.0 & 29.5 & 41.0 & 34.0 & 40.7 \\
\hline Local resident, ${ }^{\mathrm{a}} \%$ & 47.6 & 48.3 & 63.0 & 58.3 & 76.8 & 65.2 & 82.7 & 77.5 \\
\hline $\begin{array}{l}\text { Survey time (lunch/morning } \\
\text { or midday) }, \%\end{array}$ & 46.4 & 55.6 & 47.4 & 51.9 & 56.3 & 66.9 & 66.7 & 70.0 \\
\hline Survey day (weekday), ${ }_{1}^{c} \%$ & 32.7 & 60.3 & 38.6 & 58.8 & 37.5 & 37.9 & 41.4 & 40.6 \\
\hline $\begin{array}{l}\text { Celebrating special occasion } \\
\text { (yes) }{ }_{1}^{d} \%\end{array}$ & 19.6 & 18.0 & 15.7 & 14.0 & na & na & na & na \\
\hline
\end{tabular}

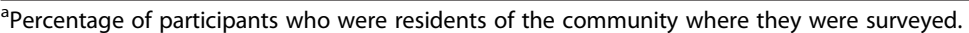

${ }^{b}$ Percentage of participants who were surveyed at lunch time (versus dinner) in restaurants or in the morning or midday (versus afternoon or evening) in stores. 'Percentage of participants who were surveyed on a weekday versus the weekend. For restaurants, Friday evening. Saturday, and Sunday were considered the weekend; for stores, all Friday-Sunday was considered the weekend.

${ }^{d}$ Percentage of restaurant participants who reported they were celebrating a special occasion during their most recent meal at the restaurant.

just exited. On a 0-4 scale (0: not at all, 4: a great deal), restaurant customers who noticed WES materials reported that, on average, ease of understanding WES materials was $3.1(\mathrm{SD}=0.9)$, level of appeal was $2.1(\mathrm{SD}=1.3)$, and helpfulness in deciding what to order was $0.9(\mathrm{SD}=1.3)$. Post-test customer survey results show $12.1 \%$ of patrons surveyed in participating restaurants reported having ordered a WES approved meal. These customers represented $48.8 \%$ of customers who noticed WES signage in a participating restaurant.

In stores, $50.5 \%$ of customers $(\mathrm{N}=201)$ had heard of WES in the intervention community at post-test, 59.1\% recognized the WES logo, and 50\% had noticed the WES logo in the store they just visited. Of store customers who noticed WES in the store, 37.8\% reported seeing deli samples of WES side dishes. On average, store customers who noticed WES materials reported that ease of understanding WES materials was $3.0(\mathrm{SD}=0.9)$, level of appeal was $2.3(\mathrm{SD}=1.1)$, and helpfulness in deciding what to order was $1.2(\mathrm{SD}=1.2)$ on a $0-4$ scale (0: not at all, 4: a great deal). About $15.5 \%$ of surveyed customers reported purchasing foods promoted by WES signs or materials. These customers represented $68.9 \%$ of store customers who noticed WES signage in the store.

\section{Effectiveness}

\section{Nutrition environment}

In restaurants, assessment of the nutrition environment showed that the average NEMS score for the 7 restaurants in the intervention community increased from 13.4 to $24.1(t=3.74, p=0.010)$ after the implementation of WES
(Figure 1). In the comparison community, scores remained similar before and after the intervention (14.9 to 16.6; $\mathrm{t}=0.560, \mathrm{p}=0.596)$.

NEMS scores in food stores decreased slightly in both communities after the intervention period, from 39.5 to 36.0 in the intervention community and from 39.5 to 37.0 in the comparison community (Figure 1).

\section{Consumers}

Results from regression models suggest improvements in satisfaction with fruit and vegetable choices and satisfaction with low-calorie choices in restaurants in both communities, with no evidence of greater improvements in the intervention community compared to the comparison community (Table 4). A trend suggesting an increase in the percentage of customers who reported having ordered any food items promoted as healthy in the intervention community compared to the comparison community was observed. However, the effect did not reach statistical significance $(\mathrm{AOR}=2.23, \mathrm{p}=.094)$. No effects on the perceived degree of healthiness of the last meal consumed in the restaurant were observed.

In stores, satisfaction with the availability and promotion of fruit/vegetable and low-calorie choices improved slightly in the intervention community and worsened in the comparison community, but after adjusting for covariates these differences were not statistically significant, suggesting no intervention effects on these variables. Likewise, no effects were observed for the likelihood of ordering foods promoted as healthy in the store. We observed a greater increase in the perceived healthiness of the food purchased in the intervention community compared to the 


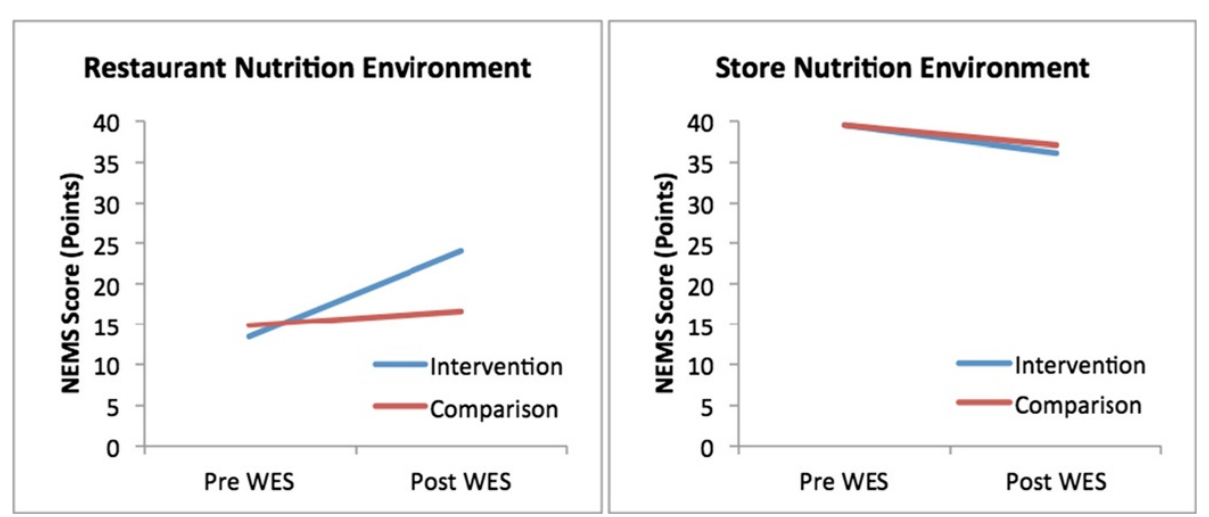

Figure 1 Nutrition environment scores before and after "Waupaca Eating Smart". Detailed Legend. Food environment scores measured with the Nutrition Environment Measurement Survey for Restaurants (NEMS-R) and for Stores (NEMS-S) in food outlets located in the intervention and comparison community (7 restaurants and 2 supermarkets per community) before and after implementation of WES. Higher scores reflect a food environment more conducive to healthy eating. Pre WES reflects nutrition environment scores 1 month prior to implementing the intervention. Post WES reflects nutrition environment scores 10 months post intervention.

comparison community. Results from the adjusted regression model suggested a significant effect of the campaign on this variable $(\mathrm{B}=0.35, \mathrm{p}=0.022$; Table 4$)$.

\section{Discussion}

This study used the RE-AIM framework to evaluate the impact of WES, a pilot intervention to improve the nutrition environment and promote healthy eating in restaurants and supermarkets in a rural Midwest community. The results indicate high levels of outlet participation, with $78 \%$ and $66 \%$ of restaurants and supermarkets invited to participate agreeing to implement the intervention. The successful level of outlet recruitment can be attributed to an in-depth formative assessment and planning process. The coalition partners had strong relationships with community partners and restaurant and store operators. These relationships and knowledge helped to identify "early adopters" that might be willing to participate in the intervention. A recruitment process involving three interviews with potential participants and a menu of intervention activities to choose from allowed for the tailoring of WES strategies to the needs and preferences of each outlet. Similar incremental approaches have been successful in previous healthy eating interventions in food stores [28].

WES demonstrated moderate to high levels of implementation and maintenance. Consistent with previous interventions in restaurants [29-32] and food stores [13,33,34], WES participating outlets successfully selected and implemented a high number of activities and most outlets maintained many WES activities 10-months after launching of the intervention. Whereas other studies allowed outlets substantial flexibility in implementing strategies, [35-41] our approach emphasized and formalized (through a signed agreement with the managers) which activities the outlet would try to implement to cover the three WES strategies (promotion, availability, and point of purchase [POP]). By requiring outlets to commit to certain types of broad strategies (e.g., promotion, availability, labeling) while offering flexibility in how these were implemented (e.g., signs on the counter, table, or staff pins), our project ensured consistency across outlets. It's likely this flexibility improved the implementation and maintenance of activities, and, at the same time, increased consistency in the use of the three broad strategies across outlets.

Despite continued WES participation, there was a slight decline at post-test in the average number of activities in place in participating restaurants and supermarkets. Other restaurant and food store interventions have reported similar challenges to ensure sustainability of the program. $[40,41]$. Some activities seem easier to sustain (e.g., window cling, healthy meal availability), while other activities (e.g., promotion by wait staff, deli sample tasting stations) may be more difficult to sustain without continued support from dedicated NPA coalition staff. In our study, the slight decline in activity implementation may be attributable to a lower level of support from the NPA coalition after the research funding ended. To improve sustainability, future efforts should attempt to partner with diverse stakeholders such as local hospitals, health departments, and businesses, build community capacity, ensure adequate staffing, and strategically plan for longterm sustainability [42].

WES achieved broad customer awareness. The variety and number of materials in restaurants and stores along with popular newspaper promotions by a local celebrity likely helped raise customer awareness of the intervention. Overall, by the end of the 10-month evaluation period over half of customers at participating restaurants and stores had heard of WES and an even larger percentage recognized the WES logo. Previous restaurant 
Table 4 Customer attitudes and purchase survey data before and after implementing "Waupaca Eating Smart"

\begin{tabular}{|c|c|c|c|c|c|c|c|c|c|}
\hline \multirow{3}{*}{ Variable } & \multirow{3}{*}{ Community } & \multicolumn{2}{|l|}{ Time } & \multirow{2}{*}{\multicolumn{2}{|c|}{$\begin{array}{l}\text { Community effect } \\
\text { (Intervention vs. } \\
\text { comparison) }\end{array}$}} & \multirow{2}{*}{\multicolumn{2}{|c|}{$\begin{array}{l}\text { Time effect (Post-test } \\
\text { vs. pretest) }\end{array}$}} & \multirow{2}{*}{\multicolumn{2}{|c|}{$\begin{array}{l}\text { Intervention effect } \\
\text { (Community } \mathrm{x} \text { time) }\end{array}$}} \\
\hline & & \multirow{2}{*}{$\begin{array}{l}\text { Pretest } \\
\text { Mean(SD)/ } \\
\%\end{array}$} & \multirow{2}{*}{$\begin{array}{l}\text { Post-test } \\
\text { Mean(SD)/ } \\
\%\end{array}$} & & & & & & \\
\hline & & & & $\begin{array}{l}\text { Adjusted } \\
\text { B/OR }\end{array}$ & $P$ & Adjusted B/OR & $\mathbf{P}$ & $\begin{array}{l}\text { Adjusted } \\
\text { B/OR }\end{array}$ & $\mathbf{P}$ \\
\hline \multicolumn{10}{|l|}{ Restaurant Customer Data ( $\mathrm{N}=721)$} \\
\hline \multirow{2}{*}{$\begin{array}{l}\text { Satisfaction with fruit/vegetable } \\
\text { choices, Mean (SD) }\end{array}$} & Intervention & $2.41(1.18)$ & $2.80(1.18)$ & $-.18^{\mathrm{a}}$ & .589 & $30^{\mathrm{a}}$ & .004 & $-.01^{\mathrm{a}}$ & .975 \\
\hline & Comparison & $2.61(1.11)$ & $2.96(1.08)$ & & & & & & \\
\hline \multirow{2}{*}{$\begin{array}{l}\text { Satisfaction with low-calorie choices, } \\
\text { Mean (SD) }\end{array}$} & Intervention & $1.76(1.25)$ & $2.34(1.23)$ & $-.077^{\mathrm{a}}$ & .726 & $.42^{\mathrm{a}}$ & .022 & $.07^{\mathrm{a}}$ & .684 \\
\hline & Comparison & $1.88(1.27)$ & $2.36(1.14)$ & & & & & & \\
\hline \multirow{2}{*}{$\begin{array}{l}\text { Did you order any food promoted } \\
\text { by materials/signs, } \%\end{array}$} & Intervention & 30.9 & 37.0 & $.83^{\mathrm{b}}$ & .717 & $.52^{\mathrm{b}}$ & .045 & $2.23^{b}$ & .094 \\
\hline & Comparison & 42.7 & 30.8 & & & & & & \\
\hline \multirow[t]{2}{*}{ How healthy was last meal, Mean (SD) } & Intervention & $2.08(1.30)$ & $2.16(1.41)$ & $.06^{\mathrm{a}}$ & .849 & $.13^{\mathrm{a}}$ & .322 & $-.20^{\mathrm{a}}$ & .189 \\
\hline & Comparison & $2.00(1.35)$ & $2.23(1.35)$ & & & & & & \\
\hline \multicolumn{10}{|l|}{ Store Customer Data $(\mathrm{N}=601)$} \\
\hline \multirow{2}{*}{$\begin{array}{l}\text { Satisfaction with fruit/vegetable choices } \\
\text { available at store, Mean (SD) }\end{array}$} & Intervention & $3.01(.91)$ & $3.23(.81)$ & $-.20^{\mathrm{a}}$ & .000 & $-.09^{\mathrm{a}}$ & .663 & $.35^{\mathrm{a}}$ & .147 \\
\hline & Comparison & $3.19(.78)$ & $3.10(.93)$ & & & & & & \\
\hline \multirow{2}{*}{$\begin{array}{l}\text { Satisfaction with promotion of fruit } \\
\text { and vegetable choices, Mean (SD) }\end{array}$} & Intervention & $2052(1.05)$ & $2.74(1.00)$ & $-.09^{\mathrm{a}}$ & .016 & $-.10^{\mathrm{a}}$ & .832 & $.36^{\mathrm{a}}$ & .458 \\
\hline & Comparison & $2.57(1.07)$ & $2.48(1.18)$ & & & & & & \\
\hline \multirow{2}{*}{$\begin{array}{l}\text { Satisfaction with selection of } \\
\text { low-calorie choices available at } \\
\text { store, Mean (SD) }\end{array}$} & Intervention & $2.43(1.07)$ & $2.58(1.03)$ & $-.18^{a}$ & .001 & $-.12^{\mathrm{a}}$ & .633 & $.28^{\mathrm{a}}$ & .353 \\
\hline & Comparison & $2.57(1.02)$ & $2.45(1.10)$ & & & & & & \\
\hline \multirow{2}{*}{$\begin{array}{l}\text { Satisfaction with promotion of } \\
\text { low-calorie products, Mean (SD) }\end{array}$} & Intervention & 2.10 (1.13) & $2.25(1.09)$ & $.01^{\mathrm{a}}$ & .499 & $-.07^{a}$ & .842 & $.26^{\mathrm{a}}$ & .474 \\
\hline & Comparison & $2.04(1.11)$ & $1.96(1.17)$ & & & & & & \\
\hline \multirow{2}{*}{$\begin{array}{l}\text { Did you purchase any food promoted } \\
\text { by materials/signs, } \%\end{array}$} & Intervention & 28.6 & 27.1 & $.73^{b}$ & .000 & $1.39^{b}$ & .157 & $.64^{\mathrm{b}}$ & .299 \\
\hline & Comparison & 34.8 & 44.7 & & & & & & \\
\hline \multirow{2}{*}{$\begin{array}{l}\text { How healthy was overall food } \\
\text { purchase, Mean (SD) }\end{array}$} & Intervention & $2.16(1.26)$ & $2.56(1.05)$ & $-.42^{\mathrm{a}}$ & .000 & $.01^{\mathrm{a}}$ & .945 & $.35^{\mathrm{a}}$ & .022 \\
\hline & Comparison & $2.54(1.07)$ & 2.58 (1.19) & & & & & & \\
\hline
\end{tabular}

${ }^{a}$ Adjusted coefficients (B) and $\mathrm{p}$ values are based on multiple linear regression models with cluster option (cluster variable $=$ outlet where data came from). For restaurant data, models were adjusted for age, gender, education, residency, meal (lunch/dinner), day (weekend/weekday), and celebrating (yes/no). For store data, models were adjusted for age, gender, education, residency, day (weekend/weekday).

${ }^{b}$ Adjusted odds rations (AOR) and $p$ values are based on logistic regression models with cluster option (cluster variable = outlet where data came from). For restaurant data, models were adjusted for age, gender, education, residency, meal (lunch/dinner), day (weekend/weekday), and celebrating (yes/no). For store data, models were adjusted for age, gender, education, residency, day (weekend/weekday).

Note. Significant interaction of the community and time effect would indicate changes overtime in intervention community compared to the comparison community. A significant interaction effect would suggest the campaign significantly impacted the outcome in the intervention compared to the comparison community.

Bold font indicates $B$ regression coefficients or odds ratios statistically significant at $p<=0.05$.

interventions have reported reach levels (i.e. awareness among restaurant customers) ranging from 20 to $100 \%$ [15,39,43-48]. The seven participating restaurants and two stores represented one-third of all restaurants and one-half of food stores in the intervention community. This would suggest at least a moderate level of exposure among community residents. Future studies should expand evaluation methods to assess the level of reach at the community level (e.g., using communitywide household or phone surveys).

This pilot study was not designed to test effectiveness, but to demonstrate feasibility and acceptability and inform a future effectiveness community trial. Still, our pilot data suggest WES was associated with an improvement in nutrition environment scores for restaurants (almost $80 \%$ increase). However, no changes in the store nutrition environment and only limited effects on customer food purchases and perceptions were observed. The results regarding improvements in the nutrition environment of restaurants participating in WES are promising. Restaurant environment scores improved partly due to signage, identification of healthier foods, and promotion of healthier foods, which are measured by the NEMS-Restaurant survey. The lack of changes in store nutrition environment scores could reflect the limited number of food stores and/or a lack of fit between the aspects of the environment measured by the NEMS-Store (NEMS-S) survey and the WES strategies implemented in 
these outlets. NEMS-S focuses on availability, quality, and price of healthy options. Large supermarkets, such those participating in WES, tend to score high in quality, availability, and price compared to small food stores. For small food stores, these three dimensions of the nutrition environment represent important intervention targets [49]. However, interventions implemented in large food stores often aim to label and promote available healthy choices to influence customer purchases and cooking practices [50-53]. WES activities in stores included distribution of healthy recipes, signage promoting produce, and in-store displays with healthy deli samples. These strategies are not reflected in NEMS-S. Consequently, this tool may not have captured changes that actually took place in the intervention store environments. Direct observation of WES activities indicated that participating stores made changes to modify their environments in the expected direction (e.g., displayed point-of-purchase signs for fruits/vegetables). In a future effectiveness trial, a larger number of food stores should be included and environment audit tools focused on marketing and promotional practices, rather than availability, quality, and price, should be used, in order to better test the potential effectiveness of this intervention approach.

Our pilot results show only minimal changes in customer attitudes and behaviors. Customer's satisfaction with fruits and vegetables and low-calorie choices improved similarly in both the intervention and comparison community. These changes may reflect a general trend in local restaurants to increase F\&V and low-calorie choices. The formative research that informed our intervention revealed restaurant owners/operators perceived a slow trend in this direction in response to increasing customer demand for these food options (Assessing the Nutrition Environment in Wisconsin Communities, unpublished data). Alternatively, the changes may reflect seasonal variations in restaurant offerings. The campaign was associated with a marginally significant increase in the likelihood of purchasing foods promoted as healthy in intervention restaurants. Ratings of the helpfulness of WES materials by restaurant customers were disappointingly low (an average of 0.9 on a 0 to 4 scale), perhaps reflecting than knowledge and availability of healthy options are insufficient to help restaurant customers make healthy choices. The limited impact suggests eating healthy is not a priority, and may be even antithetical to the notion of "eating out", for many individuals. Interventions to change, not only the restaurant food environment, but also the culture around dining out may be required to more effectively promote healthy food choices in restaurants.

Customers in intervention stores showed significant, but small improvements in the reported healthiness of their purchases compared to customers in control stores. Lack of, or modest, effectiveness at the customer level has been found for other similar interventions in supermarkets [54-56] and restaurants [57-59]. The lack of clearer results could be attributable to limited statistical power to detect small effects. Community-based interventions in real-world conditions often report small size effects compared to highly controlled efficacy trials [17]. Environmental changes may take time and greater dosage to influence individuals. The 10-month intervention may have been too brief and/or of insufficient intensity to translate into individual level behavioral changes. Implementation of the intervention in a higher number of outlets in the intervention community could have resulted in greater impact on customer attitudes and choices. Complementary and targeted interventions to increase nutrition literacy, improve attitudes, and shift social norms regarding healthy foods may be necessary to influence the impact of restaurant-and food store-based interventions on customer behaviors and attitudes.

Overall findings from this study are consistent with previous literature that shows good evidence on the feasibility and acceptability, but mixed findings regarding effectiveness of community-based healthy eating interventions in restaurants and grocery stores [11-13]. Our study was one of few implemented in a rural community and among the first to show improvements in restaurant nutrition environment scores following implementation of the intervention. These promising findings call for additional effectiveness research to expand the evidence base regarding interventions that positively impact the nutrition environment and increase understanding of the association between the nutrition environment and food purchasing behaviors.

\section{Study limitations}

This pilot study is subject to several limitations. The randomized community trial design, with only one community per condition allows for multiple validity threats. Selecting meaningful intervention and comparison communities is difficult in real world conditions. Despite our best efforts to select two comparable communities without major healthy eating activities, some healthy eating activities occurred in the comparison community during the intervention period, such as a community weightloss program, worksite wellness programs, and local food system development. The driving distance between the two communities was almost 30 miles. The short distance and differences in size (6,000 versus 26,000 residents for the intervention and comparison communities, respectively) makes it likely for residents of the smaller city to travel to the larger one for meals and shopping. However, we believe this issue should not affect the validity of our results, given that (a) the samples were drawn from the restaurants and stores in each city, (b) we measured and adjusted for whether participants lived in the city or were visiting, and (c) survey questions were referred to their 
most recent experience dining or shopping in the outlet where they were recruited (versus experiences in other restaurants and/or communities).

With the exception of the Nutrition Environment Measurement Survey (NEMS), measurement instruments and procedures were developed ad hoc for this study. The reliability and validity of these measures will have to be evaluated to inform refinement of measures and procedures in a future larger study. Other limitations include a relatively short 10 -month intervention time frame and lack of sales data. An effort was made to collect sales data quarterly from participating outlets. However, the variety of methods by which outlets tracked sales (e.g. electronically, paper slips, etc.) and our limited success in obtaining high-quality sales data dissuaded us from using these data to evaluate the effectiveness of this evaluation. Future studies should strive to include sales data and enhanced measures of food orders and purchases to better ascertain whether a similar health eating intervention changes food ordering and purchasing decisions. Despite these limitations, this study provides important pilot data to inform future research examining the impact of healthy eating interventions in restaurants and food stores in rural communities.

\section{Conclusions}

Interventions to improve the nutrition environment in restaurants and supermarkets represent a promising approach to promote healthy eating behaviors, decrease the burden of obesity, and improve population health. Results from this study suggest that community-based nutrition interventions in local restaurants and supermarkets of a rural community can have a high level of reach and moderate levels of adoption, implementation, and maintenance. Our findings demonstrate these interventions are feasible and acceptable and could be effective at improving nutrition environments in restaurants. More evidence is needed to document the impact of this intervention approach on the food environment of supermarkets and their effectiveness to influence consumer and owner attitudes and purchasing behaviors.

\section{Consent}

Written (outlet operators) and verbal (customer surveys) informed consent was obtained from the study participants for the publication of this report and any accompanying images.

\section{Competing interests}

The authors declare that they have no competing interests.

\section{Authors' contributions}

APMD designed and directed the study, supervised statistical analyses, and drafted sections of the article. AJR served as project coordinator, developed intervention materials, drafted sections of the article, and performed the statistical analyses. AMM, FJN, and SN participated in the design and implementation of the study. KM and ALE supervised the data collection. $\mathrm{BH}, \mathrm{AM}$ and $\mathrm{GG}$ recruited outlets and supported intervention development and evaluation activities in study communities. All authors contributed to the design of the intervention, participated in interpreting the data, and reviewed drafts of the article. All authors read and approved the final manuscript.

\section{Acknowledgments}

This study was funded by the University of Wisconsin School of Medicine and Public Health through the Wisconsin Partnership Program (WPP). We would also like to acknowledge support from the National Institutes of Health's Clinical and Translational Science Award (5UL 1RR025011) and National Heart Lung and Blood Institute (1 RC2 HL101468). The authors are solely responsible for the content of this article. Our funders had no role in the design, collection, analysis, or interpretation of the data. They did not contribute to the writing of the manuscript or the decision to submit the manuscript for publication.

\section{Author details}

${ }^{1}$ Department of Population Health Sciences, University of Wisconsin, Madison, WI, USA. ${ }^{2}$ Obesity Prevention Network, University of Wisconsin, Madison, WI, USA. ${ }^{3}$ University of California, Los Angeles, USA. ${ }^{4}$ Waupaca County NuAct Coalition, Waupaca, WI, USA. ${ }^{5}$ Portage County Activity and Nutrition Coalition, Stevens Point, WI, USA. ${ }^{6}$ Department of Nutritional Sciences, University of Wisconsin, Madison, WI, USA.

Received: 17 November 2014 Accepted: 27 January 2015 Published online: 12 February 2015

\section{References}

1. Institute of Medicine (U.S.). Committee on Accelerating Progress in Obesity Prevention; Food and Nutrition Board: Accelerating Progress in Obesity Prevention: Solving the Weight of the Nation. Washington, DC: The National Academies Press; 2012

2. Finkelstein EA, Trogdon JG, Cohen JW, Dietz W. Annual medical spending attributable to obesity: payer-and service-specific estimates. Health Aff Proj Hope. 2009;28:822-31.

3. Flegal KM, Carroll MD, Kit BK, Ogden CL. Prevalence of obesity and trends in the distribution of body mass index among US adults, 1999-2010. JAMA, J Am Med Assoc. 2012;307:491-7.

4. Befort CA, Nazir N, Perri MG. Prevalence of obesity among adults from rural and urban areas of the United States: findings from NHANES (2005-2008). J Rural Health Off J Am Rural Health Assoc Natl Rural Health Care Assoc. 2012;28:392-7

5. Phillips CD, McLeroy KR. Health in rural America: remembering the importance of place. Am J Public Health. 2004;94:1661-3.

6. U.S. Department of Agriculture, U.S. Department of Health and Human Services. Dietary Guidelines for Americans, 2010. 7th ed. Washington, DC: U.S. Government Printing Office; 2010.

7. Glanz K, Sallis JF, Saelens BE, Frank LD. Healthy nutrition environments: concepts and measures. Am J Health Promot AJHP. 2005;19:330-3.

8. Morland K, Wing S, Diez Roux A. The contextual effect of the local food environment on residents' diets: the atherosclerosis risk in communities study. Am J Public Health. 2002;92:1761-7.

9. Franco M, Diez-Roux AV, Nettleton JA, Lazo M, Brancati F, Caballero B, et al. Availability of healthy foods and dietary patterns: the Multi-Ethnic Study of Atherosclerosis. Am J Clin Nutr. 2009:89:897-904.

10. Holsten JE. Obesity and the community food environment: a systematic review. Public Health Nutr. 2009;12:397-405.

11. Glanz K, Hoelscher D. Increasing fruit and vegetable intake by changing environments, policy and pricing: restaurant-based research, strategies, and recommendations. Prev Med. 2004;39(2):S88-93.

12. Glanz K, Yaroch AL. Strategies for increasing fruit and vegetable intake in grocery stores and communities: policy, pricing, and environmental change. Prev Med. 2004;39(2):S75-80.

13. Escaron AL, Meinen AM, Nitzke SA, Martinez-Donate AP. Supermarket and grocery store-based interventions to promote healthful food choices and eating practices: a systematic review. Prev Chronic Dis. 2013;10:E50.

14. U.S. Census Bureau, 2010 Census Urban and Rural Classification and Urban Area Criteria. Available online at: https://www.census.gov/geo/reference/ua/ urban-rural-2010.html Last accessed on February 6, 2015 
15. Nothwehr FK, Snetselaar L, Dawson J, Schultz U. Promoting healthy choices in non-chain restaurants: effects of a simple cue to customers. Health Promot Pract. 2013;14(1):132-8.

16. Gittelsohn J, Rowan M, Gadhoke P. Interventions in Small Food Stores to Change the Food Environment, Improve Diet, and Reduce Risk of Chronic Disease. Prev Chronic Dis. 2012;9:110015.

17. Glasgow RE, Vogt TM, Boles SM. Evaluating the public health impact of health promotion interventions: the RE-AIM framework. Am J Public Health. 1999;89:1322-7.

18. McLeroy KR, Bibeau D, Steckler A, Glanz K. An ecological perspective on health promotion programs. Health Educ Q. 1988;15:351-77.

19. Minkler M, Wallerstein N. Community-Based Participatory Research for Health: From Process to Outcomes. San Francisco, CA: John Wiley \& Sons; 2010.

20. Katz DL, Murimi M, Gonzalez A, Njike V, Green LW. From controlled trial to community adoption: the multisite translational community trial. Am J Public Health. 2011;101:e17-27.

21. Kotler P, Zaltman G. Social marketing: an approach to planned social change. J Mark. 1971;35:3-12

22. Andreason AR. Marketing social change. San Francisco, CA: Jossey Bass; 1995.

23. Centers for Disease Prevention and Control, Division of Nutrition, Physical Activity, and Obesity Program Highlights, Promoting Menu Labeling Policies and Restaurant Programs, 2010. Available online at http://www.cdc.gov/ obesity/downloads/menulabeling.pdf. Last accessed on February 3, 2015.

24. Shovelin KH, Molloy DY. Winner's circle healthy dining program. J Acad Nutr Diet. 2001:101 (9, Sup 1):A-89.

25. Escaron A, Martinez-Donate A, Riggall A, Meinen A, Hall B, Nieto FJ, Nitzke S. Developing and implementing "waupaca eating smart": a restaurant and supermarket intervention to promote healthy eating through changes in the food environment. "Manuscript under review".

26. Saelens BE, Glanz K, Sallis JF, Frank LD. Nutrition Environment Measures Study in restaurants (NEMS-R): development and evaluation. Am J Prev Med. 2007;32:273-81.

27. Glanz K, Sallis JF, Saelens BE, Frank LD. Nutrition Environment Measures Survey in stores (NEMS-S): development and evaluation. Am J Prev Med. 2007;32:282-9.

28. Lee-Kwan SH, Goedkoop S, Yong R, Batorsky B, Hoffman V, Jeffries J, et al. Development and implementation of the Baltimore healthy carry-outs feasibility trial: process evaluation results. BMC Public Health. 2013;13:638.

29. Scott LW, Foreyt JP, Manis E, O'Malley MP, Gotto Jr AM. A low-cholesterol menu in a steak restaurant. J Am Diet Assoc. 1979;74:54-6.

30. Fitzpatrick MP, Chapman GE, Barr SI. Lower-fat menu items in restaurants satisfy customers. J Am Diet Assoc. 1997;97:510-4.

31. Acharya RN, Patterson PM, Hill EP, Schmitz TG, Bohm E. An evaluation of the "TrEAT Yourself Well" restaurant nutrition campaign. Health Educ Behav Off Publ Soc Public Health Educ. 2006:33:309-24

32. Hanni KD, Garcia E, Ellemberg C, Winkleby M. Targeting the taqueria: implementing healthy food options at Mexican American restaurants. Health Promot Pract. 2009;10(2):91S-9S.

33. Gittelsohn J, Vijayadeva V, Davison N, Ramirez V, Cheung LWK, Murphy S, et al. A food store intervention trial improves caregiver psychosocial factors and children's dietary intake in Hawaii. Obes Silver Spring Md. 2010;18(1):S84-90.

34. Gittelsohn J, Suratkar S, Song HJ, Sacher S, Rajan R, Rasooly IR, et al. Process evaluation of Baltimore Healthy Stores: a pilot health intervention program with supermarkets and corner stores in Baltimore City. Health Promot Pract. 2010;11:723-32

35. O'Loughlin J, Ledoux J, Barnett T, Paradis G. La Commande du Coeur ("Shop for Your Heart"): a point-of-choice nutrition education campaign in a low-income urban neighborhood. Am J Health Promot AJHP. 1996;10:175-8.

36. Mullis RM, Hunt MK, Foster M, Hachfeld L, Lansing D, Snyder $P$, et al. The shop smart for your heart grocery program. J Nutr Educ. 1987;19:225-8.

37. Lefebvre C. A Case History of Nutritional Information on Menus. Foodserv Res Int. 1986:4:153-8

38. Anderson J, Haas MH. Impact of a nutrition education program on food sales in restaurants. J Nutr Educ. 1990;22:232-8.

39. Richard L, O'loughlin J, Masson P, Devost S. Healthy menu intervention in restaurants in low-income neighbourhoods: a field experience. J Nutr Educ 1999;31:54-9.

40. Economos CD, Folta SC, Goldberg J, Hudson D, Collins J, Baker Z, et al. A community-based restaurant initiative to increase availability of healthy menu options in Somerville, Massachusetts: Shape Up Somerville. Prev Chronic Dis. 2009;6:A102.
41. Blair AM, Drass JA, Stone M, Rhoades D, Baldwin SA, Russ KM. Restaurant challenge offers healthful meal options and builds diabetes awareness. Diabetes Educ. 2011;37:581-8

42. Shediac-Rizkallah MC, Bone LR. Planning for the sustainability of communitybased health programs: conceptual frameworks and future directions for research, practice and policy. Health Educ Res. 1998;13:87-108.

43. Paul PM, Novascone MA, Ganem BC, Wimme PB. "Dine to Your Heart's Content": an assessment of the program in Virginia. J Am Diet Assoc. 1989;89:817-20

44. Forster-Coull $L$, Gillis D. A nutrition education program for restaurant patrons. J Nutr Educ. 1988:20:22B-3B.

45. Albright $\mathrm{CL}$, Flora JA, Fortmann SP. Restaurant menu labeling: impact of nutrition information on entree sales and patron attitudes. Health Educ Q. 1990;17:157-67.

46. Pulos $\mathrm{E}$, Leng K. Evaluation of a voluntary menu-labeling program in full-service restaurants. Am J Public Health. 2010;100:1035-9.

47. Nevarez CR, Lafleur MS, Schwarte LU, Rodin B, de Silva P, Samuels SE. Salud Tiene Sabor: a model for healthier restaurants in a Latino community. Am J Prev Med. 2013;44(3):S186-92.

48. Sharma S, Wagle A, Sucher K, Bugwadia N. Impact of point of selection nutrition information on meal choices at a table-service restaurant. J Foodserv Bus Res. 2011:14:146-61.

49. Gittelsohn J, Laska MN, Karpyn A, Klingler K, Ayala GX. Lessons learned from small store programs to increase healthy food access. Am J Health Behav. 2014;38:307-15.

50. Soriano E, Dozier DM. Selling nutrition and heart-healthy diet behavior at the point-of-purchase. J Appl Nutr. 1978;30:55-65.

51. Dougherty MF, Wittsten AB, Guarino MA. Promoting low-fat foods in the supermarket using various methods, including videocassettes. J Am Diet Assoc. 1990;90:1106-8.

52. Colapinto CK, Malaviarachchi D. Paint your plate: effectiveness of a point-ofpurchase display. Can J Diet Pract Res Publ Dietit Can Rev Can Prat Rech En Diététique Une Publ Diététistes Can. 2009;70:66-71.

53. Ogawa Y, Tanabe N, Honda A, Azuma T, Seki N, Suzuki T, et al. Point-ofpurchase health information encourages customers to purchase vegetables: objective analysis by using a point-of-sales system. Environ Health Prev Med. 2011;16:239-46.

54. Light L, Tenney J, Portnoy B, Kessler L, Rodgers AB, Patterson B, et al. Eat for health: a nutrition and cancer control supermarket intervention. Public Health Rep Wash DC 1974. 1989;104:443-50.

55. Steenhuis I, van Assema P, van Breukelen G, Glanz K. The effectiveness of nutrition education and labeling in Dutch supermarkets. Am J Health Promot AJHP. 2004;18:221-4.

56. Connell D, Goldberg JP, Folta SC. An intervention to increase fruit and vegetable consumption using audio communications: in-store public service announcements and audiotapes. J Health Commun. 2001;6:31-43.

57. Wagner $J \mathrm{~L}$, Winett RA. Prompting one low-fat, high-fiber selection in a fastfood restaurant. J Appl Behav Anal. 1988:21:179-85.

58. Colby JJ, Elder JP, Peterson G, Knisley PM, Carleton RA. Promoting the selection of healthy food through menu item description in a family-style restaurant. Am J Prev Med. 1986:3:171-7.

59. Fitzgerald CM, Kannan S, Sheldon S, Eagle KA. Effect of a promotional campaign on heart-healthy menu choices in community restaurants. J Am Diet Assoc. 2004;104:429-32. 